08

\title{
Исследование взаимодействия дифталоцианина лютеция с наночастицами карбида кремния оптическими методами
}

\author{
(C) С.И. Расмагин, В.И. Красовский \\ Институт общей фризики им. А.М. Прохорова РАН, \\ 119991 Москва, Россия \\ e-mail: rasmas123@yandex.ru
}

Поступило в Редакцию 10 июля 2020 г.

В окончательной редакции 2 октября 2020 г.

Принято к публикации 3 октября 2020 г.

\begin{abstract}
Проведено исследование свойств комплекса дифталоцианина лютеция и наночастиц карбида кремния с помощью оптических методов. Из данных электронной микроскопии и рентгеновского анализа были определены фазовый состав образцов, форма и размеры наночастиц карбида кремния. Анализ спектров поглощения раствора наночастиц карбида кремния с дифталоцианином лютеция показал их заметное взаимодействие. Резкий рост оптической плотности свидетельствует о сильной адсорбции молекул дифталоцианина лютеция на поверхности наночастиц карбида кремния.
\end{abstract}

Ключевые слова: дифталоцианин лютеция, карбид кремния, пиролиз.

DOI: 10.21883/JTF.2021.03.50528.223-20

\section{Введение}

В наши дни солнечную энергетику бурно развивают во всем мире различные компании (SunPower Corp., Trina Solar, Fisrt Solar, Canadian Solar и другие). Солнечные электростанции являются перспективными в качестве источников возобновляемой энергии в дополнение или в качестве частичной замены традиционных источников энергии (газ, уголь, мазут и др.) [1]. Основным элементом в солнечных электростанциях являются солнечные панели (фотопреобразователи), которые состоят из фотоэлектрических ячеек. Фотоэлектрические ячейки можно разделить на три категории [2]. Первая категория включает в себя кристаллические ячейки с $p-n$-переходом на основе монокристаллического кремния, арсенида галлия, поликристаллического кремния идр. Ко второй категории относятся фотоэлементы, использующие различные тонкопленочные технологии на базе аморфного кремния, теллурида кадмия, полупроводникового композита, состоящего из индия, галлия, меди и селена. В третью категорию входят солнечные ячейки, использующие органические краски, проводящие полимеры, наноструктурированные частицы типа наностержней, нанотрубок и квантовых точек [3].

К третьей категории также относятся фотоэлектрохимические ячейки Гретцеля (DSSC) [3]. В простой схеме ячейка Гретцеля состоит из прозрачного проводящего электрода (анод) с мезопористым слоем из полупроводника диоксида титана $\left(\mathrm{TiO}_{2}\right)$, сенсибилизированного органическим красителем, на который наносится слой электролита, контактирующий с проводящей пластиной противоэлектрода (катод). Проходя через стекло, фотоны переводят молекулы красителя в возбужденное состояние, создавая экситон, который представляет собой связанное состояние электрона и дырки. При распаде экситона возбужденный электрон переходит в зону проводимости полупроводника диоксида титана $n$ типа проводимости. Затем электрон проводимости перемещается к аноду. Одновременно с электроном дырка в процессе протекающих в электролите окислительновосстановительных реакций переходит в электролит и перемещается к катоду.

Исследователи и инженеры предполагают, что ячейки третьей категории превзойдут по конкурентоспособности другие источники энергии за счет более высокой эффективности, низкой цены и простоты технологии [4]. В развитие ячеек Гретцеля направляют большие усилия с целью оптимизации характеристик каждой из компонент DSSC. Например, необходимо улучшить условия распада экситона за счет введения в краситель различного рода наночастиц полупроводников [5], поэтому необходимо исследовать детали взаимодействия наночастиц полупроводников с молекулами красителя. В настоящей работе исследуется конкретный вариант взаимодействия наночастиц карбида кремния и молекул дифталоцианина лютеция [6]. Карбид кремния используется в различных электронных приборах, особенно если требуется работа при высоких температурах, больших мощностях, высокочастотном и СВЧ диапазонах и т.д. [7]. Карбид кремния ( $\mathrm{SiC})$ обладает большой шириной запрещенной зоны $E_{g}$ в сравнении с кремнием, германием и арсенидом галлия. Наиболее распространенные политипы $\mathrm{SiC}$ имеют ширину запрещенной зоны в интервале $2-4 \mathrm{eV}\left(3 \mathrm{C}-\mathrm{SiC}-E_{g}=2.2 \mathrm{eV}, 6 \mathrm{H}-\mathrm{SiC}-E_{g}=3 \mathrm{eV}\right.$ и $\left.4 \mathrm{H}-\mathrm{SiC}-E_{g}=3.6 \mathrm{eV}\right)$. Разные политипы монокристаллического $\mathrm{SiC}$ позволяют создавать различные источники излучения. Например, созданы радиационностойкие светодиоды и фотоприемники с разными длинами волн для $3 \mathrm{C}-\mathrm{SiC}-\lambda_{\max }=563 \mathrm{~nm}$ (желтое из- 
лучение), $6 \mathrm{H}-\mathrm{SiC}-\lambda_{\max }=413 \mathrm{~nm}$ (фиолетовое излучение) и $4 \mathrm{H}-\mathrm{SiC}-\lambda_{\max }=380 \mathrm{~nm}$ (ультрафиолетовое излучение). Наряду с изучением монокристаллического карбида кремния в последнее время растет количество исследований наночастиц карбида кремния $(\mathrm{nSiC})$, помогающих выявить новые сферы их применения [8-11]. Дифталоцианин лютеция $\left(\mathrm{LuPc}_{2}\right)$ обладает хорошими поглощающими оптическими свойствами [12], и в качестве поглотителя света может использоваться в ячейках Гретцеля.

\section{1. Экспериментальная часть}

Наночастицы карбида кремния были получены в результате лазерно-индуцированного пиролиза путем смешивания газов моносилана $\mathrm{SiH}_{4}$ и ацетилена $\mathrm{C}_{2} \mathrm{H}_{2}$ при температуре $t=1500^{\circ} \mathrm{C}$. В результате синтеза были созданы два образца с разным фазовым составом (условно назовем их образец 1 и образец 2). Для смешивания наночастиц карбида кремния с дифталоцианином лютеция использовали образец 1 . Навеску $3 \mathrm{mg}$ образца 1 с наночастицами карбида кремния $(\mathrm{nSiC})$ растворили в $10 \mathrm{ml}$ тетрагидрофурана (ТHF) марки ХЧ. Раствор диспергировали на ультразвуковой установке (У3) мощностью $100 \mathrm{~W}$ пятью интервалами по $30 \mathrm{~s} \mathrm{c}$ перерывами по $30 \mathrm{~s}$. Полученную суспензию подвергли центрифугированию при $8000 \mathrm{rpm}$ в течение $5 \mathrm{~min}$. Жидкость над осадком декантировали. Получился желтый слабоопалесцирующий раствор. Полученный коллоидный раствор разбавили в два раза THF, снова отцентрифугировали в течение $45 \mathrm{~min}$ при $8000 \mathrm{rpm}$. Декантированный раствор использовали для получения образцов. Для получения раствора фталоцианина лютеция $\left(\mathrm{Pc}_{2} \mathrm{Lu}, \mathrm{m} . \mathrm{m} .1199\right)$ навеску $6 \mathrm{mg} \mathrm{Pc}_{2} \mathrm{Lu}$ растворили в $20 \mathrm{ml} \mathrm{THF.} \mathrm{Полученный} \mathrm{раствор} \mathrm{использовали} \mathrm{для} \mathrm{при-}$ готовления образцов. Были приготовлены контрольные и смешанные растворы $\mathrm{nSiC}+\mathrm{LuPc}_{2}$ в растворителе тетрагидрофуране (ТHF): $1-\mathrm{LuPc}_{2}+\mathrm{THF} 1 \mathrm{ml}$, $2-\left(\mathrm{LuPc}_{2}+\mathrm{THF}\right) \quad 0.8 \mathrm{ml}+(\mathrm{nSiC}+\mathrm{THF}) \quad 0.2 \mathrm{ml}$, $3-\left(\mathrm{LuPc}_{2}+\mathrm{THF}\right) \quad 0.5 \mathrm{ml}+(\mathrm{nSiC}+\mathrm{THF}) \quad 0.5 \mathrm{ml}$, $4-\left(\mathrm{LuPc}_{2}+\mathrm{THF}\right) 0.2 \mathrm{ml}+(\mathrm{nSiC}+\mathrm{THF}) 0.8 \mathrm{ml}$ и $5-$ $\mathrm{nSiC}+\mathrm{THF} 1 \mathrm{ml}$.

Концентрация $\mathrm{LuP}_{\mathrm{C} 2}$ составила $6 \cdot 10^{-5} \mathrm{~mol} / 1$. Для приготовления ячейки Гретцеля использовали следующие материалы: две стеклянные пластины с напыленным слоем ITO (оксид индия-олова), порошок $\mathrm{TiO}_{2}$, раствор дифталоцианина лютеция $\left(\mathrm{LuPc}_{2}\right)$ в тетрагидрофуране $\left(\mathrm{LuPc}_{2}+\mathrm{THF}\right), \quad$ раствор $\mathrm{KI}+\mathrm{I}_{2}$ в этиленгликоле $\left(\mathrm{KI}+\mathrm{I}_{2}+\mathrm{C}_{2} \mathrm{H}_{6} \mathrm{O}_{2}\right)$. Порошок $\mathrm{TiO}_{2}$ размешали в этиленгликоле, а затем в лимонной кислоте. Полученную смесь нанесли на пленку ITO на стекле и провели термообработку при температуре $t=400^{\circ} \mathrm{C}$ в течение $30 \mathrm{~min}$. После термообработки начальный композит $\mathrm{TiO}_{2}+\mathrm{ITO}$ охладили на воздухе в течение $24 \mathrm{~h}$. Затем композит $\mathrm{TiO}_{2}+\mathrm{ITO}$ пропитали раствором $\mathrm{LuPc}_{2}+\mathrm{THF}$ и высушили в течение $24 \mathrm{~h}$ при комнатной температуре.
В результате получили промежуточный композит светло-синего цвета $\mathrm{ITO}+\mathrm{TiO}_{2}+\mathrm{LuPc}_{2}$. После этого композит $\mathrm{ITO}+\mathrm{TiO}_{2}+\mathrm{LuPc}_{2}$ пропитали раствором $\mathrm{KI}+\mathrm{I}_{2}$ в этиленгликоле и на него напылили слой углерода. На полученный композит положили еще одно стекло с ITO. Финальный композит условно обозначили $\mathrm{ITO}+\mathrm{TiO}_{2}+\mathrm{LuPc}_{2}+\mathrm{KI}+\mathrm{I}_{2}+\mathrm{C}+\mathrm{ITO} . \quad$ В результате технологических операций получили композит в виде сэндвича, который фактически представлял собой ячейку Гретцеля. Первая (контрольная) ячейка Гретцеля была условно обозначена как $\left[\mathrm{ITO}+\mathrm{TiO}_{2}\right]+\mathrm{LuPc}_{2}+$ $+\left[\mathrm{KI}+\mathrm{I}_{2}\right]+[\mathrm{C}+\mathrm{ITO}]$, а вторую ячейку Гретцеля обозначали как $\left[\mathrm{ITO}+\mathrm{TiO}_{2}\right]+\left[\mathrm{LuPc}_{2}+\mathrm{nSiC}\right]+\left[\mathrm{KI}+\mathrm{I}_{2}\right]+$ $+[\mathrm{C}+\mathrm{ITO}]$. Другими словами, вторая ячейка Гретцеля по сравнению с контрольной имеет в своем составе наночастицы карбида кремния. Фазовый состав образцов, форма и размеры наночастиц карбида кремния определены методом электронной микроскопии с использованием электронного микроскопа JEOL JSM-5910 LV. Рентгенофазовый анализ образцов выполнен на рентгеновском дифрактометре D2 Phaser $\left(\mathrm{CuK}_{u}\right)$. Спектры поглощения растворов изучены на спектрометре Option Optics 2000 с динамическим диапазоном $300-1100 \mathrm{~nm}$. В качестве источника излучения использовали вольфрамовую лампу мощностью $10 \mathrm{~mW}$.

\section{2. Результаты и их обсуждение}

Были сняты микрофотография и дифрактограмма наночастиц карбида кремния (nSiC) (рис. 1 и 2).

На рис. 1 видны девять из десяти известных линий политипа $\beta$-SiC кубической модификации карбида кремния, полученных отражением от систем плоскостей с индек-

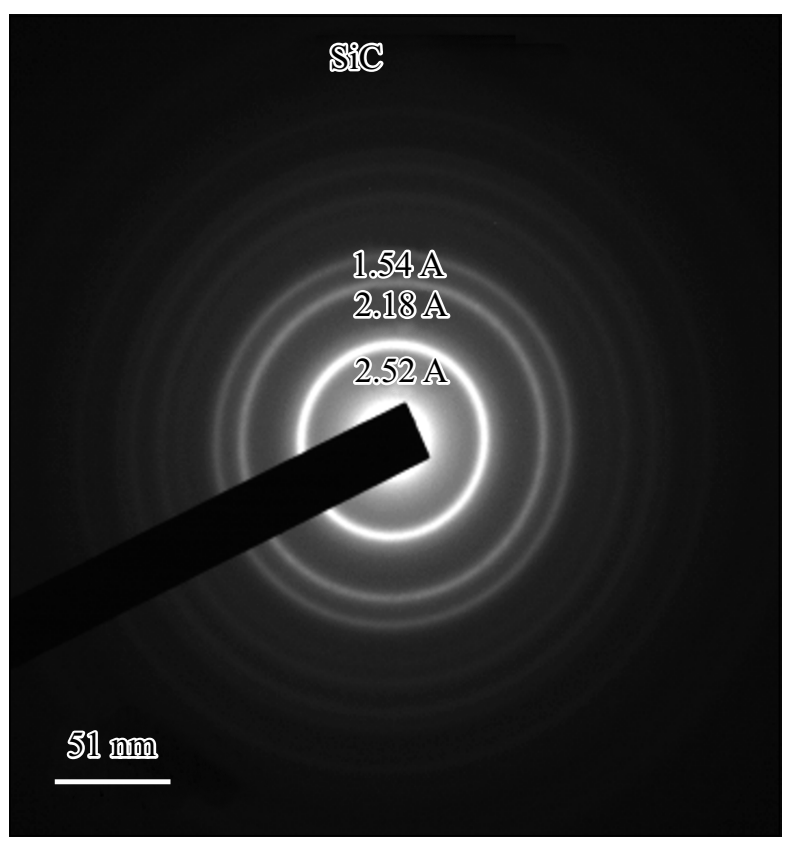

Рис. 1. Дифрактограмма наночастиц карбида кремния. 


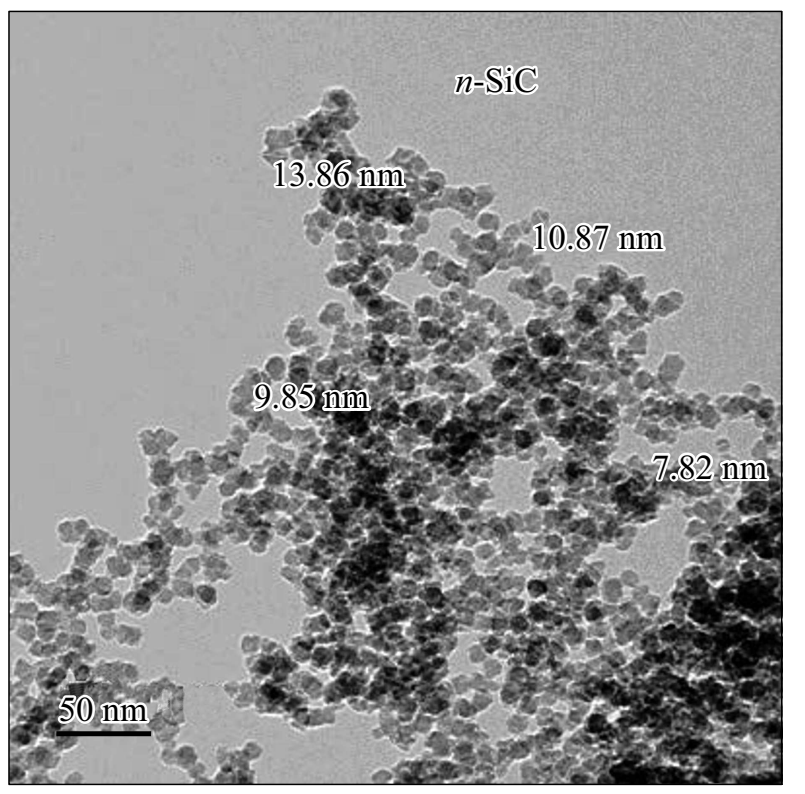

Рис. 2. Микрофотография СЭМ наночастицы карбида кремния.

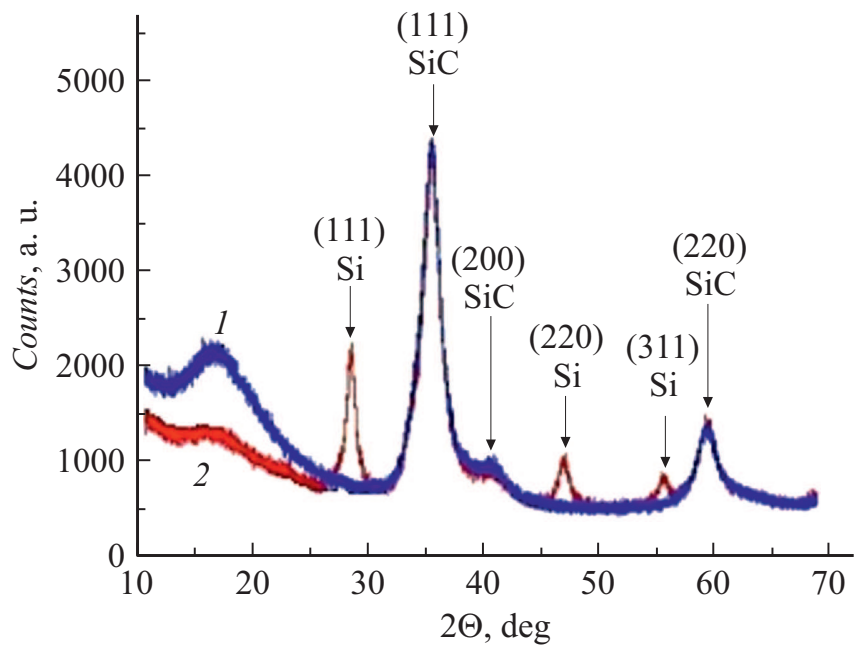

Pис. 3. Дифрактограммы двух разных образцов с наночастицами карбида кремния: 1 - образец с наночастицами карбида кремния, 2 - образец с наночастицами карбида кремния и наночастицами кремния.

сами Миллера $\beta$-SiC (111), (200), (220), (311), (400), (311), (420), (422), (333). Количество колец свидетельствует о высоком качестве структуры нанокристаллов $\beta$ $\mathrm{SiC}$. Однако большая ширина первого кольца допускает также наложение первых трех наиболее интенсивных линий $2 \mathrm{H}-\mathrm{SiC}(100),(002),(101)$. Отсутствие остальных линий $2 \mathrm{H}-\mathrm{SiC}$ указывает на несовершенство структуры нанокристаллов $2 \mathrm{H}-\mathrm{SiC}$, для снижения дефектности структуры которых требуется высокая температура.

Из рис. 2 определили размеры нанокристаллов $\mathrm{nSiC}$ в диапазоне 7-14 nm; видно, что наночастицы карбида кремния имеют в основном сферическую форму.

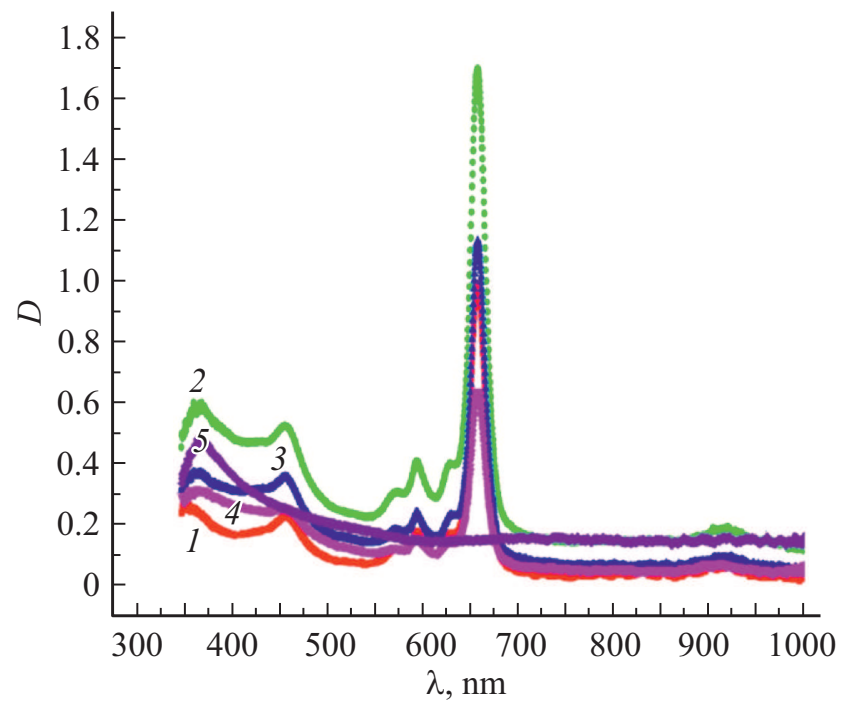

Рис. 4. Спектры поглощения: $1-\mathrm{LuPc}_{2}+\mathrm{THF} 1 \mathrm{ml}$, $2-\left(\mathrm{LuPc}_{2}+\mathrm{THF}\right) 0.8 \mathrm{ml}+(\mathrm{nSiC}+\mathrm{THF}) 0.2 \mathrm{ml}$, $3-\left(\mathrm{LuPc}_{2}+\mathrm{THF}\right) 0.5 \mathrm{ml}+(\mathrm{nSiC}+\mathrm{THF}) 0.5 \mathrm{ml}$, $4-\left(\mathrm{LuPc}_{2}+\mathrm{THF}\right) 0.2 \mathrm{ml}+(\mathrm{nSiC}+\mathrm{THF}) 0.8 \mathrm{ml}$ и $5-\mathrm{nSiC}+\mathrm{THF} 1 \mathrm{ml}$.

Рентгенофазовый анализ (РФА) образцов 1 и 2 с наночастицами карбида кремния провели на рентгеновском дифрактометре D2 Phaser $\left(\mathrm{CuK}_{u}\right)$. Дифрактограммы нанокристаллов карбида кремния показаны на рис. 3.

Методом РФА показано, что основной фазой является карбид кремния $\beta-\mathrm{SiC}$ (линии (111), (200) и (220)). Размеры кристаллитов составили 6-10 nm. Наиболее интенсивные пики $2 \mathrm{H}-\mathrm{SiC}$, лежащие при углах $2 \theta=33.563^{\circ}$ для $2 \mathrm{H}(100), 35.626^{\circ}$ для $2 \mathrm{H}(002)$ и $38.131^{\circ}$ для $2 \mathrm{H}(101)$, сливаются с линией $\beta-\mathrm{SiC}(111)$ в один широкий максимум в пределах углов $32.1^{\circ}<2 \theta<38.7^{\circ}$. Размер наночастиц карбида кремния можно определить из формулы Дебая-Шеррера:

$$
L=(R \lambda) /(\Delta \cos 2 \Theta),
$$

где $L-$ средний размер наночастиц $\mathrm{SiC}$ (диаметр для сферической наночастицы), $R=0.94-$ коэффициент сферичности, $\lambda=0.15418 \mathrm{~nm}, \Delta-$ полуширина пика, [rad], $2 \Theta-$ угол Брэгга (положение пика). Например, для $2 \Theta=35.7^{\circ}$ размер $L$ наночастицы карбида кремния порядка $7 \mathrm{~nm}$. Полученные размеры хорошо совпадают с размерами, полученными с помощью данных СЭМ.

Во втором образце, наряду с наночастицами карбида кремния, образуются наночастицы кремния. Отметим еще раз, что для создания комплексов дифталоцианина лютеция и наночастиц карбида кремния использовали образец 1.

Используя оптические методы, мы получили спектры поглощения растворов, описанных в экспериментальной части (рис. 4).

Анализ рис. 4 показал наличие следующих максимумов: $\lambda_{m}=656 \mathrm{~nm}$ ( $Q$-полоса $) \mathrm{LuPc}_{2}, \lambda_{m}=350 \mathrm{~nm}(B$ - 
полоса) $\mathrm{LuPc}_{2}$ и $\lambda_{m}=368 \mathrm{~nm}$ для $\mathrm{nSiC}[9]$. Заметное увеличение поглощения в интервале длин волн $350-570 \mathrm{~nm}$ для нанокристаллов карбида кремния (рис. 4, кривая 5) свидетельствует о присутствии в растворе нанокристаллов $3 \mathrm{C}-\mathrm{SiC}$ и $2 \mathrm{H}-\mathrm{SiC}$. Наличие пика при $368 \mathrm{~nm}$ указывает на высокую концентрацию наночастиц карбида кремния, имеющих ширину запрещенной зоны $3.37 \mathrm{eV}$, что подтверждает присутствие нанокристаллов $2 \mathrm{H}-\mathrm{SiC}$. Температура измерения полученных растворов $\mathrm{LuPc}_{2}+\mathrm{nSiC}$ была $22^{\circ} \mathrm{C}$. Пик поглощения $(Q$ полоса $\left.\lambda_{m}=656 \mathrm{~nm}\right) \mathrm{LuPc}_{2}$ соответствует электронному переходу с HOMO $2 b_{1}$ на LUMO $6 e_{3}\left(\pi-\pi^{*}\right.$-переходы) с энергетическим интервалом $E_{\mathrm{HOMO}-\mathrm{LUMO}}=1.9 \mathrm{eV}$. Данный электронный переход происходит между синглетным основным и синглетным возбужденным состояниями. Оптическая плотность $Q$-полосы сначала растет до значения $D=1.7$ с увеличением концентрации $\mathrm{nSiC}$, а затем резко уменьшается до $D=0.6$.

Пик поглощения $\left(B V\right.$-полоса $\left.\lambda_{m}=454 \mathrm{~nm}\right) \mathrm{LuPc}_{2}$ coответствует электронному переходу с НОМО $5 e_{1}$ на LUMO $2 a_{2}\left(\pi-\pi^{*}\right.$-переходы) с энергетическим интервалом $E_{\mathrm{HOMO}-\mathrm{LUMO}}=2.73 \mathrm{eV}$. Данный электронный переход происходит между синглетным основным и синглетным возбужденным состояниями. Оптическая плотность $B V$-полосы сначала растет до значения $D=0.55$ с увеличением концентрации $\mathrm{nSiC}$ и уменьшением концентрации молекул $\mathrm{LuPc}_{2}$, а затем уменьшается до $D=0.22$. Как для $Q$-полосы, так и для $B V$-полосы увеличение оптической плотности носит немонотонный и нелинейный характер. Полученную зависимость можно объяснить следующим образом. Наночастицы карбида кремния, также как и другие полупроводниковые наночастицы, обладают повышенной адсорбиционной и адгезионной активностью. Благодаря своей большой удельной поверхности и избытку поверхностной энергии, наночастицы карбида кремния легко адсорбируют на своей поверхности молекулы дифталоцианина лютеция. Процесс адсорбции происходит благодаря вандер-ваальсовым силам. Число адсорбированных молекул $\mathrm{LuPc}_{2}$ на наночастице $\mathrm{SiC}$ можно определить по формуле

$$
N_{\mathrm{LuPc}_{2}}=N_{0} \exp \left(-E_{A} / k T\right)
$$

где $N_{\mathrm{LuPc}_{2}}-$ число молекул (плотность) у поверхности двух фаз (дифталоцианин лютеция - наночастицы карбида кремния), $N_{0}-$ число молекул (плотность) на поверхности наночастицы карбида кремния, $E_{A}-$ энергия адсорбции или адсорбционный потенциал, $k-$ константа Больцмана, $T$ - температура в Кельвинах.

Поэтому оптическая плотность $Q$-полосы и $B V$ полосы растет благодаря увеличению концентрации молекул $\mathrm{LuPc}_{2}$ на границе $\left(\mathrm{LuPc}_{2}-\mathrm{nSiC}\right)$, несмотря на уменьшение концентрации молекул $\mathrm{LuPc}_{2}$. Дальнейшее уменьшение концентрации молекул $\mathrm{LuPc}_{2}$ и увеличение концентрации $\mathrm{nSiC}$ приводит к уменьшению оптической плотности $Q$-полосы и $B V$-полосы образцов 2 и 5. Уменьшение оптической плотности $(D) Q$ - и $B V$ - полос произошло из-за более сильного падения концентрации молекул $\mathrm{LuPc}_{2}$. Молекул $\mathrm{LuPc}_{2}$ становится намного меньше и процесс адсорбции на поверхности $\mathrm{nSiC}$ не компенсирует резкое уменьшение поглощения. Процессом адгезии для полученных наночастиц карбида кремния размером порядка $10 \mathrm{~nm}$ можно пренебречь, так как сила адгезии мала. Сила адгезии рассчитывается в теории Джонсона-Кендалла-Робертсса по формуле

$$
F_{A D}=A r / 6 d^{2},
$$

где $F_{A D}-$ сила адгезии, $A-$ константа Гамакера, $r-$ радиус наночастиц $\mathrm{SiC}, d-$ расстояние между поверхностью $\mathrm{nSiC}$ и молекулами $\mathrm{LuPc}_{2}$, составляющее порядка $0.17 \mathrm{~nm}$. Расчет по формуле (2) дает силу адгезии порядка $F_{A D} \approx 10^{-9} \mathrm{~N}$. Из расчета видно, что величина силы адгезии незначительна.

Пик поглощения с длиной волны $\lambda_{m}=350 \mathrm{~nm}$ соответствует электронному переходу HOMO $4 a_{1}$ на LUMO $6 e_{1}\left(\pi-\pi^{*}\right.$-переходы $)$ с энергетическим интервалом $E_{\text {HOMO-LUMO }}=3.6 \mathrm{eV}$. Электронный переход $4 a_{1} \rightarrow 6 e_{1}$ $(B$-полоса) возникает у дифталоцианина лютеция благодаря взаимодействию между лигандами. Максимум поглощения, соответствующий длине волны $\lambda_{m}=366 \mathrm{~nm}$, вызван электронным переходом в наночастицах карбида кремния с энергией перехода $E$ порядка $3.38 \mathrm{eV}$. Близость максимумов поглощения $\mathrm{nSiC}$ и $B$-полосы дифталоцианина лютеция способствует обмену энергией между их энергетическими уровнями, что видно на рис. 4 для $B$-полосы дифталоцианина лютеция.

На рис. 5 показан график изменения оптической плотности от длины волны.

Кривая на рис. 5 имеет форму, характерную для резонанса Фано. Известно, что резонанс Фано возникает

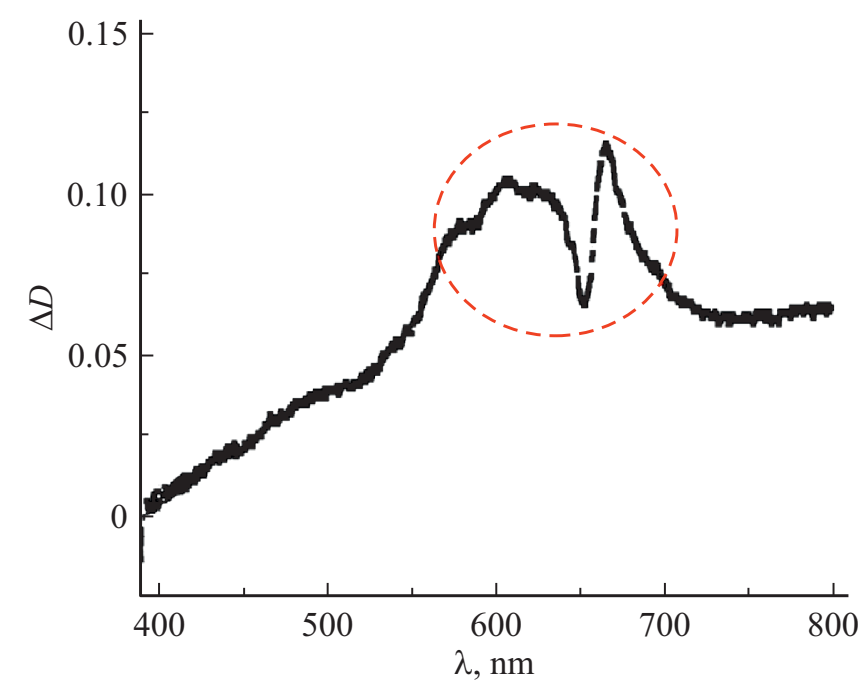

Рис. 5. Волновая зависимость изменения оптической плотности $\Delta D(\lambda)$, где $\Delta D(\lambda)=\left(D_{\mathrm{LuPc}_{2}+\mathrm{nSiC}+\mathrm{THF}}\right)-\left(D_{\mathrm{LuPc}_{2}+\mathrm{THF}}\right)-$ $-\left(D_{\mathrm{nSiC}+\mathrm{THF}}\right), \quad D_{\mathrm{LuPc}_{2}+\mathrm{THF}}-$ оптическая плотность образца $1, D_{\mathrm{LuPc}_{2}+\mathrm{nSiC}+\mathrm{THF}}$ - оптическая плотность образца 2 , $D_{\mathrm{LuPc}_{2}+\mathrm{nSiC}+\mathrm{THF}}-$ оптическая плотность образца 5. Штриховой круг - резонанс Фано. 
при сильном экситон-плазмонном взаимодействии. Так, например, в работе [13] была экспериментально установлена нелинейная интерференция между экситонной и плазмонной модами. В нашем случае при облучении светом в дифталоцианине лютеция (органический полупроводник) и в наночастицах карбида кремния создаются экситоны, при этом может происходить перенос энергии между наночастицами карбида кремния и молекулами дифталоцианина лютеция по механизму, описанному в работе [14]. Поэтому было высказано предположение, что наблюдаемый нами резонанс Фано вызван экситонэкситонным взаимодействием (т. е. взаимодействием молекул дифталоцианина лютеция с наночастицами карбида кремния).

$\mathrm{Y}$ контрольной ячейки Гретцеля $\left[\mathrm{ITO}+\mathrm{TiO}_{2}\right]+$ $+\mathrm{LuPc}_{2}+\left[\mathrm{KI}+\mathrm{I}_{2}\right]+[\mathrm{C}+\mathrm{ITO}]$ с использованием образца 1 в качестве поглотителя измерили напряжение при облучении светом. У ячейки Гретцеля $\left[\mathrm{ITO}+\mathrm{TiO}_{2}\right]+\left[\mathrm{LuPc}_{2}+\mathrm{nSiC}\right]+\left[\mathrm{KI}+\mathrm{I}_{2}\right]+[\mathrm{C}+\mathrm{ITO}]$ с использованием образца 2, в котором присутствовали наночастицы карбида кремния, также измерили напряжение при освещении. Напряжение у контрольной ячейки было порядка $1 \mathrm{~V}$, а напряжение у ячейки с наночастицами карбида кремния оказалось порядка $1.3 \mathrm{~V}$. Результаты показали, что ячейка Гретцеля с наночастицами карбида кремния дает большее напряжение, чем без них при одинаковом освещении.

\section{Заключение}

Анализируя экспериментальные данные, приходим к следующим заключениям.

1. Наночастицы карбида кремния, полученные лазерно-индуцированным пиролизом, имеют сферическую форму. Размеры полученных наночастиц карбида кремния находятся в диапазоне 7-14 nm. Синтезированные нанокристаллы карбида кремния имеют смешанный фазовый состав $\beta-\mathrm{SiC}$ и $2 \mathrm{H}-\mathrm{SiC}$.

2. Наблюдается ярко выраженная адсорбция молекул дифталоцианина лютеция на поверхности наночастиц карбида кремния, что отражается в сильном росте оптической плотности $Q$ - и $B V$-полос в спектре поглощения молекул $\mathrm{LuPc}_{2}$.

3. Наличие резонанса Фано может быть вызвано экситон-экситонным взаимодействием в композите $\mathrm{LuPc}_{2}+\mathrm{nSiC}$

\section{Конфликт интересов}

Авторы заявляют, что у них нет конфликта интересов.

\section{Список литературы}

[1] V.A. Milichko, A.S. Shalin, I.S. Mukhin, A.E. Kovrov, A.A. Krasilin, A.V. Vinogradov, P.A. Belov, C.R. Simovskii. Phys. Usp., 59, 727 (2016).

DOI: $10.3367 /$ UFNe.2016.02.037703
[2] M.A. Green. Third Generation Photovoltaics (Springer, Berlin, 2003)

[3] B. Di Bartolo, J. Collins, L. Silvestri. Nano-Structures for Optics and Photonics: Optical Strategies for Enhancing Sensing, Imaging, Communication and Energy Conversion (Springer, 2015)

[4] J. Valenta, S. Mirabella. (Eds.) Nanotechnology and Photovoltaic Devices: Light Energy Harvesting with Group IV Nanostructures (Taylor \& Francis Group, 2015)

[5] L. Jin, D. Chen. Electrochimica Acta, 72, 40 (2012). DOI:10.1016/j.electacta.2012.03.167

[6] H. Abderrazak, E.S. Hmida. Silicon Carbide: Synthesis and Properties P. 361-388 in Properties and Applications of Silicon Carbide. Ed. R. Gerhardt. InTech. Janeza Trdine. (2011). DOI: $10.5772 / 15736$

[7] Z.C. Feng. SiC Power Materials: Devices and applications. Ed. Springer Series in Material Science (Springer-Verlag Berlin Heidelberg, 2004) ISBN: 3-540-20666-3

[8] D.D. Awschalom, L.C. Bassett, A.S. Dzurak, E.L. Hu, J.R. Petta. Science, 339, 1174 (2013).

[9] P.G. Baranov, A.P. Bundakova, A.A. Soltamova, S.B. Orlinskii, I.V. Borovykh, R. Zondervan, R. Verberk, J. Schmidt. Phys. Rev. B, 83, 125 (2011).

[10] M. Widmann, S.-Y. Lee, T. Rendler, N.T. Son, F. Fedder, S. Paik, L.-P. Yang, N. Zhao, S. Yang, I. Booker, A. Denisenko, M. Jamali, S.A. Momenzadeh, I. Gerhardt, T. Ohshima, A. Gali, E. Janzń, J. Wrachtrup. Nature Materials, 14, 164 (2015).

[11] С.И. Расмагин. Неорган. Матер., 56 (9), 1 (2020). DOI: $10.31857 / \mathrm{S} 0002337 \mathrm{X} 20090146$

[12] A.V. Borisov, M.V. Korel'Chuk, N.E. Galanin, G.P. Shaposhnikov. Rus. J. General Chem., 84(5), 953 (2014).

[13] N.T. Fofang, N.K. Grady, Z. Fan, N.J. Halas. NanoLett., 11, 1556 (2011). DOI: 10.1021/nl104352j

[14] E. Cohen, P. Komm, N. Rosenthal-Strauss, J. Dehnel, E. Lifshitz. J. Phys. Chem., 122|,(10), 5753 (2018). 